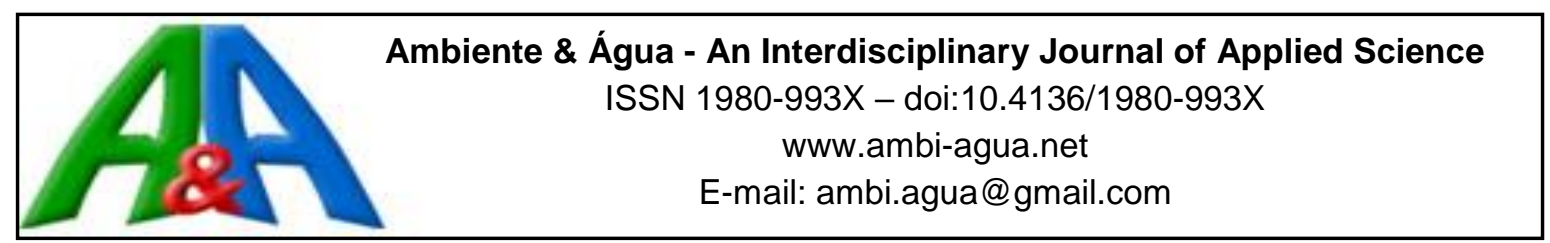

\title{
Vegetação arbustivo-arbórea em uma restinga de Jaguaruna, litoral sul do Estado de Santa Catarina, Brasil
}

\author{
doi:10.4136/ambi-agua.1952 \\ Received: 06 Jun. 2016; Accepted: 29 Oct. 2016 \\ Robson dos Santos; Guilherme Alves Elias*; \\ Aline Votri Guislon; Iara Zaccaron Zanoni \\ Universidade do Extremo Sul Catarinense (UNESC), Criciúma, SC, Brasil \\ Programa de Pós-Graduação em Ciências Ambientais, Herbário Pe. Dr. Raulino Reitz (CRI) \\ *Autor correspondente: e-mail: guilherme@unesc.net, \\ rsa@unesc.net,vg_aline@hotmail.com,iara_zanoni@hotmail.com
}

\section{RESUMO}

Para ampliar o conhecimento sobre a planície costeira do Estado de Santa Catarina, foi realizado um estudo fitossociológico do componente arbustivo-arbóreo na restinga da Lagoa do Arroio Corrente, no município de Jaguaruna, sul do Estado. Para amostragem da vegetação, foi usado o método de parcelas, incluindo os indivíduos com diâmetro a altura do solo (DAS) mínimo de $2,5 \mathrm{~cm}$. Constatou-se, diferença de altura na fitofisionomia do trecho superior $(5 \mathrm{~m})$ e do trecho inferior $(10 \mathrm{~m})$ das dunas, optando-se por realizar a amostragem separadamente. A vegetação da restinga da Lagoa do Arroio Corrente apresentou, no trecho superior, estratificação de baixo porte $(1$ a $5 \mathrm{~m})$, destacando-se indivíduos arbustivos, conferindo aparência densa à vegetação, devido ao desenvolvimento aglomerado dessas plantas e, no trecho inferior, com indivíduos arbóreos emergentes, conferindo dois estratos, um mais baixo com predomínio de vegetação arbustiva $(2$ a $5 \mathrm{~m})$ e um segundo com indivíduos arbóreos (até $10 \mathrm{~m}$ ). A riqueza florística resultou em 17 famílias, 25 gêneros e 32 espécies. A área basal total foi de 4,3 $\mathrm{m}^{2}$.ha $\mathrm{a}^{-1}$ (trecho superior) e $23,2 \mathrm{~m}^{2}$.ha' $\mathrm{h}^{-1}$ (trecho inferior). Guapira opposita (Vell.) Reitz apresentou maior valor de importância, destacando-se também nos demais parâmetros fitossociológicos analisados (frequência, densidade e dominância). As análises efetuadas contribuem com dados estruturais para as restingas de Santa Catarina, podendo auxiliar na caracterização da vegetação dos cordões arenosos do sul do Brasil.

Palavras-chave: biodiversidade, fitossociologia, Floresta Atlântica, vegetação litorânea.

\section{Shrub-tree vegetation in a restinga of Jaguaruna, southern coast of Santa Catarina, Brazil}

\begin{abstract}
In order to develop a greater understanding of the coastal land of the state of Santa Catarina, we carried out a phytosociological study of shrub-tree component in the restinga of the Lagoa do Arroio Corrente, in the municipality of Jaguaruna, in the southern part of the state. The study used the "plots" method, including shrub-trees with a diameter at soil height
\end{abstract}


(DSH) minimum of $2.5 \mathrm{~cm}$. We found a difference in the height of shrub-trees individuals in the upper $(10 \mathrm{~m})$ and lower $(5 \mathrm{~m})$ sections, and opted to carry out sampling in these two vegetation types separately. The restinga's vegetation of the Lagoa do Arroio Corrente had, in the upper section, low size stratification (1 to $5 \mathrm{~m}$ ), due to shrubby individuals, with dense vegetation cover, due to the development of clusters of plants and, in the lower section, with emerging individual trees, resulting in two strata: a lower stratum, with predominance of shrubby (2 to 5) and an upper stratum, with tree individuals (up to $10 \mathrm{~m}$ ). The floristic richness resulted in 17 botanical families, 25 genera and 32 species. The total basal area was $4.3 \mathrm{~m}^{2} \cdot \mathrm{ha}^{-1}$ (upper section) and $23.2 \mathrm{~m}^{2} \cdot \mathrm{ha}^{-1}$ (lower section). Guapira opposita (Vell.) Reitz exhibited the highest importance value, with other outstanding phytosociological parameters (frequency, density, and dominance). The analyses performed contribute to structural data for restingas of Santa Catarina, assisting in the characterization of vegetation of sand bars of Southern Brazil.

Keywords: Atlantic Forest, biodiversity, coastal vegetation, phytosociology.

\section{INTRODUÇÃO}

A vegetação da restinga no sul do Brasil possui características peculiares, e reúne um conjunto de ecossistemas com alta heterogeneidade ambiental, ocorrendo desde dunas até planícies costeiras. As condições ambientais, nas restingas, são extremas, com altas temperaturas, ventos constantes, elevada salinidade e solos com deficiência em nutrientes (Scarano et al., 2001). No entanto, a vegetação estabelecida nestes ambientes apresenta adaptabilidade e resistência, compondo um ecossistema com função de proteção da costa e da biodiversidade (Sevegnani e Comtois, 2013; Sevegnani et al., 2013). Mesmo apresentando tal importância, a restinga tem sofrido recorrentes impactos, principalmente, pela introdução de espécies animais e vegetais exóticas, pela pressão agrícola e pelo crescimento das cidades (Santos et al., 2012).

Muitos são os papéis da vegetação de restinga sobre o ecossistema onde está inserida. Alguns autores associam essa vegetação à estabilização do substrato nesses ambientes, como a proteção da ação de ventos, que é considerada importante modificador da paisagem (Lindeman, 1906; Rambo, 1954; Assumpção e Nascimento, 2000; Santos et al., 2012), além de manter a drenagem natural, contribuindo também para a preservação da fauna endêmica e migratória (Falkenberg, 1999; Rocha et al., 2005).

A restinga apresenta uma diversidade fisionômica que expressa uma composição, que geralmente, combina espécies próprias do litoral com outras provenientes de outros ecossistemas, como por exemplo, do bioma Mata Atlântica, e é representada por espécies aclimatadas à faixa litorânea (Araujo, 2000; Sacramento et al., 2007; IBGE, 2012), no entanto, podem ocorrer variações fenotípicas devido à diferença do habitat original (Freire, 1990; Leite e Klein, 1990; Scarano, 2002; Klein et al., 2007).

Para melhor conhecimento das restingas são necessárias descrições sobre a vegetação que se pode dar, basicamente, por meio de métodos florísticos e estruturais (Kent e Coker, 1992; Santos et al., 2012). Dessa forma, a listagem da flora e a caracterização estrutural contribuem para designar e classificar as vegetações litorâneas, além de diferenciar suas fisionomias (Silva e Britez, 2005; Magnago et al., 2011; Melo Júnior et al., 2015), fornecendo mais características sobre as restingas de Santa Catarina.

Em Santa Catarina, estudos florísticos e fitossociológicos que destacam a importância e diversidade da restinga, já foram tratados por Reitz (1954, 1961), Bresolin (1979), Falkenberg (1999), Korte et al. (2013) e Melo Júnior et al. (2015).

Salienta-se que, no sul do estado de Santa Catarina, há poucos estudos sobre a vegetação 
de restinga, sendo, portanto, de grande importância à produção científica sobre este tipo de ecossistema, uma vez que, constantemente vem sofrendo com as ações antrópicas (Cunha, 2005). Desta forma, diante da lacuna existente, este estudo teve como objetivo descrever as características estruturais do componente arbustivo-arbóreo de uma restinga no litoral sul do estado de Santa Catarina.

\section{MATERIAL E MÉTODOS}

O estudo foi realizado no componente arbustivo-arbóreo da restinga da Lagoa do Arroio Corrente, município de Jaguaruna, litoral sul do estado de Santa Catarina, com distância de 2 $\mathrm{km}$ do mar. O solo foi classificado, como Espodossolo (Embrapa, 2013). O clima é Cfa (segundo a classificação de Köppen), ou seja, mesotérmico úmido, sem estação seca definida e com verão quente (Alvares et al., 2013), com índices pluviométricos médios de $1.400 \mathrm{~mm}$ ao ano e umidade relativa do ar de $82 \%$ (Back, 2009), influenciado pela umidade marítima. A vegetação se desenvolve sobre dunas fixas de aproximadamente 30 metros de altura, tendo sua base em contato com a água da lagoa e foi descrita por Reitz (1961) como "lagoa de barragem".

Constatou-se, no reconhecimento da área de estudo, diferença de altura na fitofisionomia do trecho superior $(5 \mathrm{~m})$ e do trecho inferior $(10 \mathrm{~m})$ das dunas, optando-se por realizar a amostragem separadamente (Figura 1).

A vegetação da restinga da Lagoa do Arroio Corrente apresentou, no trecho superior, estratificação de baixo porte (1 a $5 \mathrm{~m}$ ), destacando-se indivíduos arbustivos, conferindo aparência densa à vegetação, devido ao desenvolvimento aglomerado dessas plantas e, no trecho inferior, com indivíduos arbóreos emergentes, conferindo dois estratos, um mais baixo com predomínio de vegetação arbustiva (2 a $5 \mathrm{~m}$ ) e um segundo, com indivíduos arbóreos (até $10 \mathrm{~m}$ ). A comparação entre os dois trechos foi feita por meio do índice de similaridade de Jaccard que expressa a semelhança entre ambientes, baseando-se no número de espécies comuns.

A atualização taxonômica seguiu a Lista das Espécies da Flora do Brasil (Flora do Brasil 2020 em construção, 2016). O material coletado fértil foi depositado no Herbário Pe. Dr. Raulino Reitz (CRI) da Universidade do Extremo Sul Catarinense (UNESC).

$\mathrm{O}$ estudo fitossociológico foi realizado empregando-se o método de parcelas, proposto por Mueller-Dombois e Ellenberg (2002). Foram traçadas em cada trecho da duna (superior e inferior) 30 parcelas de $5 \mathrm{~m} \times 5 \mathrm{~m}\left(750 \mathrm{~m}^{2}\right)$, distribuídas em três blocos de 10 parcelas contíguas, distantes 30 metros entre si e mensurados todos os indivíduos vivos com diâmetro a altura do solo (DAS) $\geq 2,5 \mathrm{~cm}$. O diâmetro das plantas foi obtido com o auxílio de paquímetro digital e a altura foi estimada com bastão graduado. Indivíduos ramificados no nível do solo foram considerados na amostragem quando, pelo menos, um dos ramos atendia ao critério de inclusão estabelecido (DAS $\geq 2,5 \mathrm{~cm}$ ), conforme descrito por Moro e Martins (2011), que orientam que, se no nível do solo, dois eixos aparecem conspicuamente ligados (rameta), tendo uma base comum, ambos são considerados como um único indivíduo. Já, quando cada eixo emerge separadamente no nível do solo (geneta), eles são considerados como indivíduos distintos e devem ser medidos separadamente.

Para análise da organização do componente arbustivo-arbóreo foi calculado a densidade, a frequência e a dominância absoluta, o valor de importância (VI), o índice de diversidade de Shannon-Wiener (H') e o índice de equabilidade de Pielou (J'). Foram elaborados histogramas do número de indivíduos por intervalos de altura (amplitude de um metro) e de diâmetro (amplitude de 2,5 cm). Foram consideradas como espécies raras aquelas representadas por apenas um indivíduo na amostragem (Martins, 1991). 


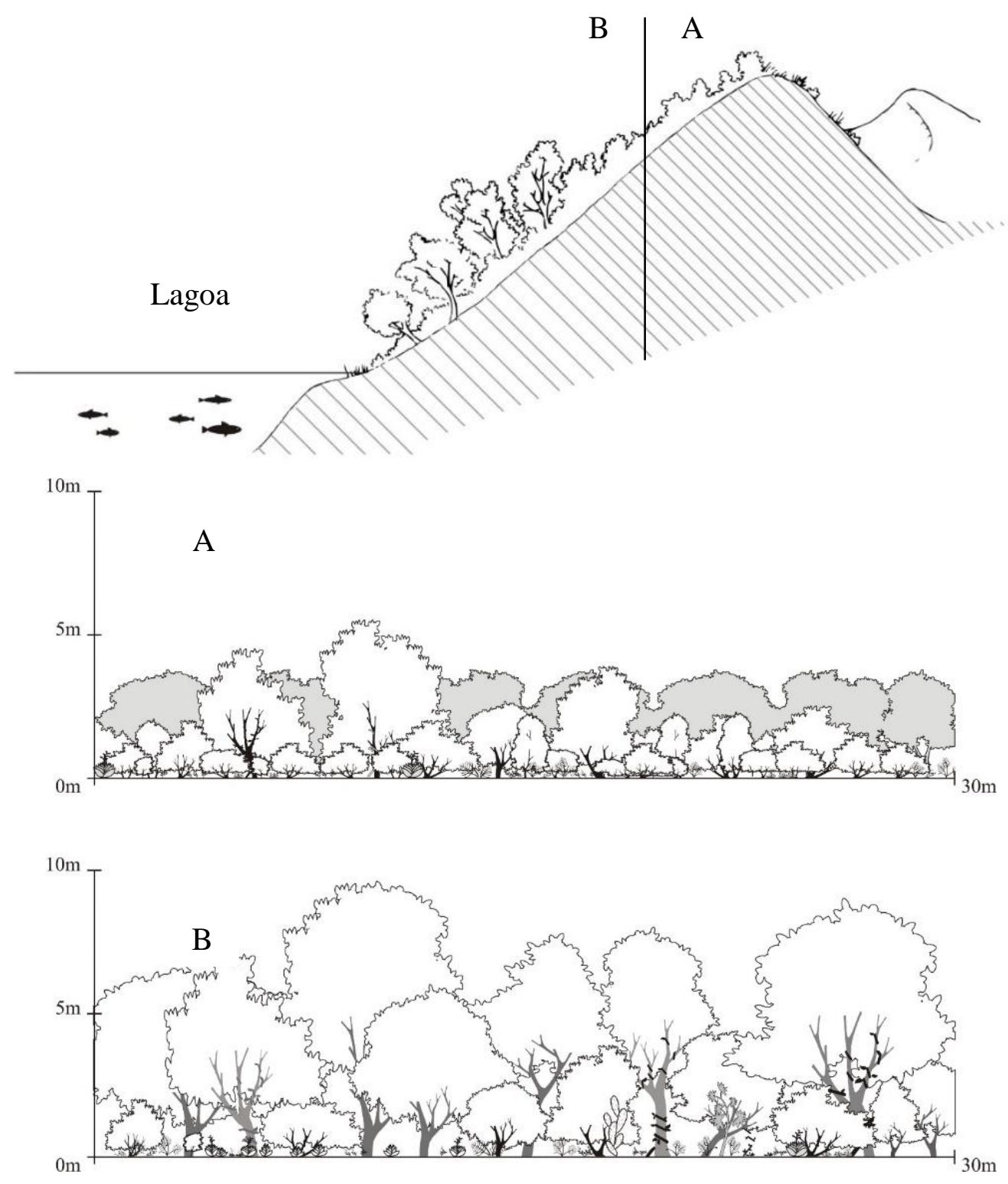

Figura 1. Perfil esquemático das fitofisionomias da restinga da Lagoa do Arroio Corrente, município de Jaguaruna, Santa Catarina. A = trecho superior e $\mathrm{B}=$ trecho inferior das dunas.

Aspectos das síndromes de dispersão das espécies arbustivo-arbóreas foram abordados e discutidos de acordo com van der Pijl (1972). Para esta análise, foram reunidas informações de cada espécie, principalmente as relativas ao tipo de fruto, com base em pesquisa bibliográfica e observações realizadas em campo.

Para o enquadramento das espécies nos grupos ecológicos, conforme proposto por Budowski (1965), consultou-se estudos realizados na região sul de Santa Catarina, bem como por observações feitas nos trabalhos de campo no momento da amostragem fitossociológica.

\section{RESULTADOS E DISCUSSÃO}

A composição florística foi representada por 32 espécies e 25 gêneros distribuídos em 17 famílias (Tabela 1), com maior número de espécies para Myrtaceae (cinco espécies), Aquifoliaceae e Euphorbiaceae com quatro espécies cada e Sapindaceae com três espécies. 
Essas quatro famílias representaram 50\% do total de espécies amostradas. Entre as demais famílias, três foram representadas por duas espécies cada (19\%) e dez por uma única espécie (31\%). A família com maior número de indivíduos foi Nyctaginaceae (52\%), seguida por Euphorbiaceae (13\%), Myrtaceae (6\%) e Lauraceae (4\%).

Tabela 1. Caracterização das fitofisionomias da restinga da Lagoa do Arroio Corrente, Jaguaruna, Santa Catarina. $\mathrm{DA}=$ densidade absoluta (indivíduos.ha ${ }^{-1}$ e DoA $=$ dominância absoluta $\left(\mathrm{m}^{2} \cdot \mathrm{ha}^{-1}\right)$, índice de diversidade de Shannon-Wiener $\left(\mathrm{H}^{\prime}\right)$, em nats.ind ${ }^{-1}$ e de equabilidade de Pielou (J').

\begin{tabular}{lcccccccc}
\hline \multirow{2}{*}{ Trecho } & \multirow{2}{*}{ Famílias } & \multirow{2}{*}{ Gêneros } & Espécies & DA & DoA & & \multicolumn{2}{c}{ Índice } \\
\cline { 1 - 3 } \cline { 8 - 10 } Superior & 12 & 16 & 18 & 1.425 & 4,3 & & 1,50 & 0,52 \\
Inferior & 15 & 23 & 27 & 2.732 & 23,2 & & 2,30 & 0,70 \\
\hline Total & $\mathbf{1 7}$ & $\mathbf{2 5}$ & $\mathbf{3 2}$ & $\mathbf{2 . 0 7 8}$ & $\mathbf{1 5 , 4}$ & & $\mathbf{2 , 6 7}$ & $\mathbf{0 , 7 0}$ \\
\hline
\end{tabular}

A família Myrtaceae, com riqueza superior às demais, geralmente permanece com representantes entre as cinco espécies de maior valor de importância, sobressaindo-se na composição florística e estrutural em diversos locais da costa brasileira (Silva et al., 2008; Scherer et al., 2005, 2009; Santos et al., 2012; Martins et al., 2013), além de suas espécies obterem, na restinga, um ambiente propício para seu desenvolvimento (Reitz, 1961).

A similaridade florística (50\%) evidenciou alta semelhança entre os dois trechos avaliados evidenciando existência de um padrão fitogeográfico baseado na distribuição das espécies. No trecho superior foram exclusivas as famílias Fabaceae e Lamiaceae, representadas por três espécies exclusivas, enquanto que no trecho inferior foram exclusivas as famílias Erythroxylaceae, Rosaceae, Sapindaceae e Sapotaceae, representadas por 13 espécies exclusivas (Tabela 2).

Tabela 2. Parâmetros fitossociológicos, ordenados por valor de importância (VI), das espécies amostradas no trecho superior e inferior das dunas da restinga da Lagoa do Arroio Corrente, Jaguaruna, Santa Catarina.

\begin{tabular}{llcccccc}
\hline \multicolumn{1}{c}{ Trecho Superior } & & & & & & \\
\hline \multicolumn{1}{c}{ Espécie } & Família & FA & DA & DoA & VI & SD & GE \\
\hline Guapira opposita (Vell.) Reitz & Nyctaginaceae & 76,7 & 960 & 2,82 & 59,0 & Zoo & Sin \\
Campomanesia littoralis D.Legrand & Myrtaceae & 10,0 & 40 & 0,47 & 6,5 & Zoo & Cli \\
Vitex megapotamica (Spreng.) Moldenke* & Lamiaceae & 13,3 & 80 & 0,12 & 5,4 & Zoo & Sin \\
Handroanthus pulcherrimus (Sandwith) Mattos & Bignoniaceae & 10,0 & 53 & 0,18 & 4,6 & Ane & Sin \\
Myrsine parvifolia A.DC.* & Primulaceae & 10,0 & 40 & 0,15 & 4,0 & Zoo & Sin \\
Lithrea brasiliensis Marchand & Anacardiaceae & 6,7 & 27 & 0,10 & 2,7 & Zoo & Pio \\
Myrsine umbellata Mart. & Primulaceae & 6,7 & 40 & 0,06 & 2,6 & Zoo & Sin \\
Psidium cattleianum Sabine & Myrtaceae & 6,7 & 27 & 0,06 & 2,4 & Zoo & Sta \\
Ilex paraguariensis A.St.-Hil. & Aquifoliaceae & 6,7 & 27 & 0,02 & 2,1 & Zoo & Pio \\
Sebastiania serrata Müll.Arg. & Euphorbiaceae & 3,3 & 27 & 0,03 & 1,5 & Aut & Pio \\
Casearia sylvestris Sw. & Salicaceae & 3,3 & 13 & 0,06 & 1,4 & Zoo & Sin \\
\hline Continua
\end{tabular}

Continua... 


\begin{tabular}{|c|c|c|c|c|c|c|c|}
\hline ontınuaçao.. & & & & & & & \\
\hline Sapium glandulosum (L.) Morong & Euphorbiaceae & 3,3 & 13 & 0,05 & 1,4 & Aut & Pio \\
\hline Enterolobium contortisiliquum (Vell.) Morong* 1 & Fabaceae & 3,3 & 13 & 0,03 & 1,2 & Aut & Pio \\
\hline Myrcia splendens (Sw.) DC. & Myrtaceae & 3,3 & 13 & 0,03 & 1,2 & Zoo & Sin \\
\hline Ilex pseudobuxus Reissek* & Aquifoliaceae & 3,3 & 13 & 0,02 & 1,1 & Zoo & Pio \\
\hline Ocotea pulchella (Nees \& Mart.) Mez & Lauraceae & 3,3 & 13 & 0,02 & 1,1 & Zoo & Pio \\
\hline Pera glabrata (Schott) Poepp. ex Baill. & Peraceae & 3,3 & 13 & 0,02 & 1,1 & Zoo & Sta \\
\hline Condalia buxifolia Reissek & Rhamnaceae & 3,3 & 13 & 0,01 & 1,0 & Zoo & Pio \\
\hline Total & & 177 & 1425 & 4,3 & 100 & & \\
\hline Trec & echo Inferior & & & & & & \\
\hline Espécie & Família & FA & DA & DoA & VI & SD & GE \\
\hline Guapira opposita (Vell.) Reitz & Nyctaginaceae & 76,7 & 1200 & 12,41 & 41,1 & Zoo & Sin \\
\hline Sapium glandulosum (L.) Morong & Euphorbiaceae & 33,3 & 280 & 3,62 & 12,4 & Aut & Pio \\
\hline $\begin{array}{l}\text { Allophylus edulis (A.St.-Hil. et al.) Hieron. ex } \\
\text { Niederl.* }\end{array}$ & Sapindaceae & 23,3 & 120 & 0,63 & 5,0 & Zoo & Sin \\
\hline Ocotea indecora (Schott) Mez* & Lauraceae & 13,3 & 160 & 0,80 & 4,6 & Zoo & Cli \\
\hline Sebastiania serrata Müll.Arg. & Euphorbiaceae & 10,0 & 133 & 1,17 & 4,4 & Zoo & Sin \\
\hline Casearia sylvestris $\mathrm{Sw}$. & Salicaceae & 10,0 & 93 & 0,94 & 3,6 & Zoo & Sin \\
\hline Condalia buxifolia Reissek & Rham & 13,3 & 80 & 0,31 & 2,9 & Zoo & Pio \\
\hline Psidium cattleianum Sabine & Myrtaceae & 10,0 & 67 & 0,06 & 2,0 & Zoo & Sta \\
\hline Cupania vernalis Cambess.* & Sapindaceae & 10,0 & 53 & 0,17 & 2,0 & Zoo & Pio \\
\hline Ilex paraguariensis A.St.-Hil. & Aquifoliaceae & 10,0 & 67 & 0,04 & 2,0 & Zoo & Pio \\
\hline $\begin{array}{l}\text { Chrysophyllum marginatum (Hook. \& Arn.) } \\
\text { Radlk.* }\end{array}$ & Sapotaceae & 6,7 & 53 & 0,33 & 1,9 & Zoo & Pio \\
\hline Campomanesia littoralis D.Legrand & Myrta & 6,7 & 53 & 0,29 & 1,8 & Zoo & Cli \\
\hline Lithrea brasiliensis Marchand & Anacardiaceae & 6,7 & 40 & 0,38 & 1,8 & Zoo & Pio \\
\hline Ilex theezans Mart. ex Reissek* & Aquifoliaceae & 6,7 & 40 & 0,17 & 1,5 & Zoo & Pio \\
\hline Ilex dumosa Reissek* & Aquifoliaceae & 6,7 & 27 & 0,27 & 1,5 & Zoo & Pio \\
\hline Myrsine umbellata Mart. & Primulaceae & 6,7 & 27 & 0,12 & 1,2 & Zoo & Sin \\
\hline Actinostemon concolor (Spreng.) Müll.Arg.* & Euphorbiaceae & 3,3 & 53 & 0,14 & 1,2 & Aut & Sta \\
\hline Pera glabrata (Schott) Poepp. ex Baill. & Peraceae & 6,7 & 27 & 0,10 & 1,2 & Zoo & Sta \\
\hline Matayba guianensis Aubl.* & Sapindaceae & 3,3 & 13 & 0,44 & 1,2 & Zoo & Sta \\
\hline Myrcia splendens (Sw.) DC. & Myrtaceae & 6,7 & 27 & 0,06 & 1,2 & Zoo & Sin \\
\hline Handroanthus pulcherrimus (Sandwith) Mattos & Bignoniaceae & 6,7 & 27 & 0,05 & 1,2 & Ane & Sin \\
\hline Erythroxylum deciduum A.St.-Hil.* & Erythroxylaceae & 3,3 & 27 & 0,16 & 0,9 & Zoo & Pio \\
\hline Myrcia palustris DC.* & Myrtaceae & 3,3 & 13 & 0,22 & 0,9 & Zoo & Pio \\
\hline Ocotea pulchella (Nees \& Mart.) Mez & Lauraceae & 3,3 & 13 & 0,17 & 0,8 & Zoo & Pio \\
\hline Eugenia catharinae O.Berg* & Myrtaceae & 3,3 & 13 & 0,13 & 0,7 & Zoo & Sin \\
\hline Prunus ulei Koehne* & Rosaceae & 3,3 & 13 & 0,01 & 0,5 & Zoo & Cli \\
\hline Schinus polygamus (Cav.) Cabrera* & Anacardiaceae & 3,3 & 13 & 0,01 & 0,5 & Zoo & Sin \\
\hline total & & 297 & 2132 & 23,2 & 100 & & \\
\hline
\end{tabular}

Nota: $\mathrm{FA}=$ frequência absoluta $(\%), \mathrm{DA}=$ densidade absoluta (indivíduos.ha ${ }^{-1}$ ), DoA $=$ dominância absoluta $\left(\mathrm{m}^{2} \cdot \mathrm{ha}^{-1}\right)$; síndrome de dispersão $(\mathrm{SD})$, em que, $\mathrm{Zoo}=$ zoocoria, Ane $=$ anemocoria e Aut $=$ autocoria e grupo ecológico $(\mathrm{GE})$, em que, Pio= pioneira, $\mathrm{Sin}=$ secundária inicial, $\mathrm{Sta}=$ secundária tardia e $\mathrm{Cli}=$ clímax. *espécie exclusiva do trecho amostrado (superior ou inferior). 
A diferença na composição das espécies e do porte dos indivíduos, relacionada aos trechos superior e inferior das dunas, pode estar relacionada à maior fertilidade decorrente do acúmulo de matéria orgânica no trecho inferior, o que pode favorecer o aparecimento e o desenvolvimento de espécies que atribuem um aspecto diferencial na fitofisionomia, fato também observado em outros estudos da costa brasileira (Sampaio, 2005; Almeida Junior et al., 2011). Adicionalmente, os ventos em excesso, vindos do mar, contribuem com a fitofisionomia presente no trecho superior das dunas.

Apesar do tamanho reduzido do remanescente amostrado, a restinga da Lagoa do Arroio Corrente apresentou boa representatividade de espécies devido a maior riqueza quando comparada às demais áreas de mata arenosa amostradas no sul do Brasil (Scherer et al., 2009).

A espécie com maior valor de importância, tanto no trecho superior quanto no trecho inferior, foi Guapira opposita (Vell.) Reitz, destacando-se das demais também nos demais parâmetros fitossociológicos (frequência, densidade e dominância). Já as espécies consideradas raras, aquelas representadas por um único indivíduo, perfizeram $44 \%$ no trecho superior e $22 \%$ no trecho inferior (Tabela 2). Dentre estas, destaca-se Prunus ulei Koehne, no trecho inferior da duna, que consta na lista das espécies ameaçadas de extinção no estado de Santa Catarina (CONSEMA, 2014), descrita como característica e exclusiva das restingas arbustivas, apresentando possivelmente restrita, descontínua e inexpressiva dispersão, estendendo-se em Santa Catarina, desde Laguna até Sombrio (Reitz, 1996).

Guapira opposita é característica da floresta ombrófila densa e da restinga litorânea no sul do Brasil, onde apresenta vasta e expressiva dispersão, além de elevada abundância (Reitz, 1970). A espécie figura entre as dominantes do componente arbustivo, formando densos agrupamentos nos terrenos arenosos e pouco ondulados nas proximidades das praias (Reitz, 1970). Na restinga da Lagoa do Arroio Corrente, G. opposita faz parte da vegetação típica de dunas fixas, situadas mais para o interior e atrás das dunas móveis ou semifixas. Ocorre nas associações juntamente com Sapium glandulosum (L.) Morong, Allophylus edulis (A.St.-Hil. et al.) Hieron. ex Niederl., Ocotea indecora (Schott) Mez, Sebastania serrata Müll.Arg., Casearia sylvestris Sw., Campomanesia littoralis D.Legrand e Vitex megapotamica (Spreng.) Moldenke. Os altos valores de densidade obtidos por espécies de ampla distribuição refletem a elevada plasticidade ecológica dessas espécies e a sua capacidade de adaptação a ambientes estressantes.

A ocorrência de G. opposita, em diferentes ecossistemas, como na floresta ombrófila densa (Colonetti et al., 2009; Martins et al., 2013; Bosa et al., 2015) e na restinga (Santos et al., 2012), indica que a espécie apresenta plasticidade de caracteres morfológicos e fisiológicos, no sentido de que os filtros seletivos não restringiram seu estabelecimento e sobrevivência nos processos evolutivos. Uma vez que espécies com variação fenotípica têm maior habilidade para ocorrer ao longo de um gradiente de condições ambientais. A variação fenotípica de $G$. opposita possibilita seu estabelecimento em ambientes com diferentes intensidades luminosas, desde a restinga arbustiva até a restinga alta (Santos et al., 2010). Quando sombreados pelo dossel da floresta, a forma da copa mostra-se mais aberta, com muitas ramificações do caule, apresentando uma arquitetura de modo a constituir uma única camada coletora de luz. Nos indivíduos da restinga, expostos diretamente à luz, a forma da copa mostra-se mais fechada, também com muitas ramificações do caule, porém mostrando as folhas dispostas em diversas camadas coletoras de luz (Santos et al., 2010).

A altura média encontrada no componente arbustivo-arbóreo no trecho superior da duna foi $2,9 \mathrm{~m}$ e a máxima, $5,5 \mathrm{~m}$; no trecho inferior à altura média foi $4,9 \mathrm{~m}$ e a máxima $10 \mathrm{~m}$. A maioria dos indivíduos (92\%) no trecho superior foi registrada entre a segunda e a quinta classe de altura, correspondendo aos intervalos de 2 a $5 \mathrm{~m}$ (Figura 2); no trecho inferior, a maioria dos indivíduos (74\%) foi registrada entre a quarta e a sétima classe de altura, correspondendo aos intervalos de 3 a $7 \mathrm{~m}$ (Figura 2). 


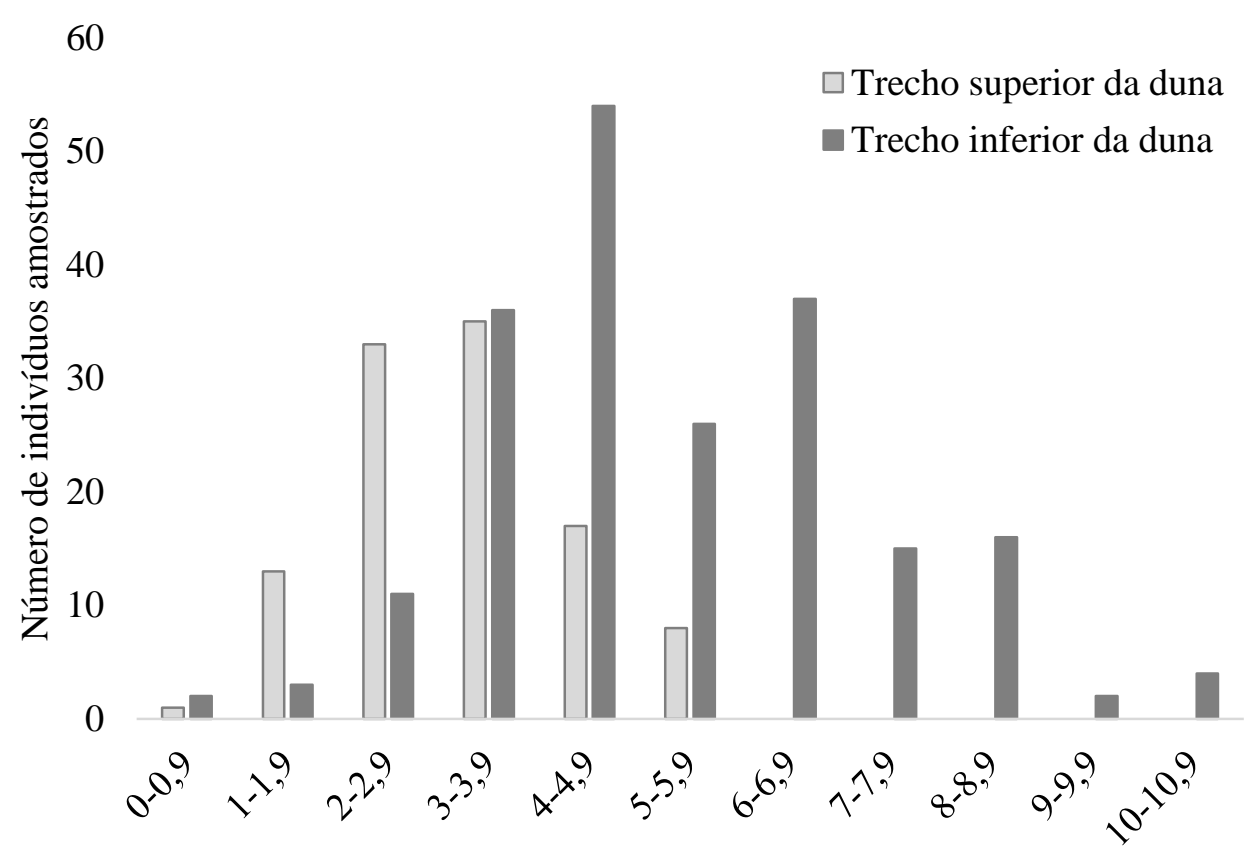

Classes de altura

Figura 2. Distribuição em classes de altura do componente arbustivo-arbóreo na restinga da Lagoa do Arroio Corrente, município de Jaguaruna, Santa Catarina, Brasil.

O diâmetro médio no trecho superior foi de $4,9 \mathrm{~cm}$ e o máximo de $15,5 \mathrm{~cm}$ e no trecho inferior o diâmetro médio foi de 7,3 cm e o máximo de $23,9 \mathrm{~cm}$, representados principalmente por indivíduos de Guapira opposita. A maioria dos indivíduos (62\%) no trecho superior foi registrada na primeira classe de diâmetro e no trecho inferior a maioria dos indivíduos (34\%) foi registrada na segunda classe de diâmetro, seguido pela terceira classe com $22 \%$. A área basal total foi de $4,3 \mathrm{~m}^{2} \cdot \mathrm{ha}^{-1}$ e $23,2 \mathrm{~m}^{2} \cdot \mathrm{ha}^{-1}$, nos trechos superior e inferior, respectivamente.

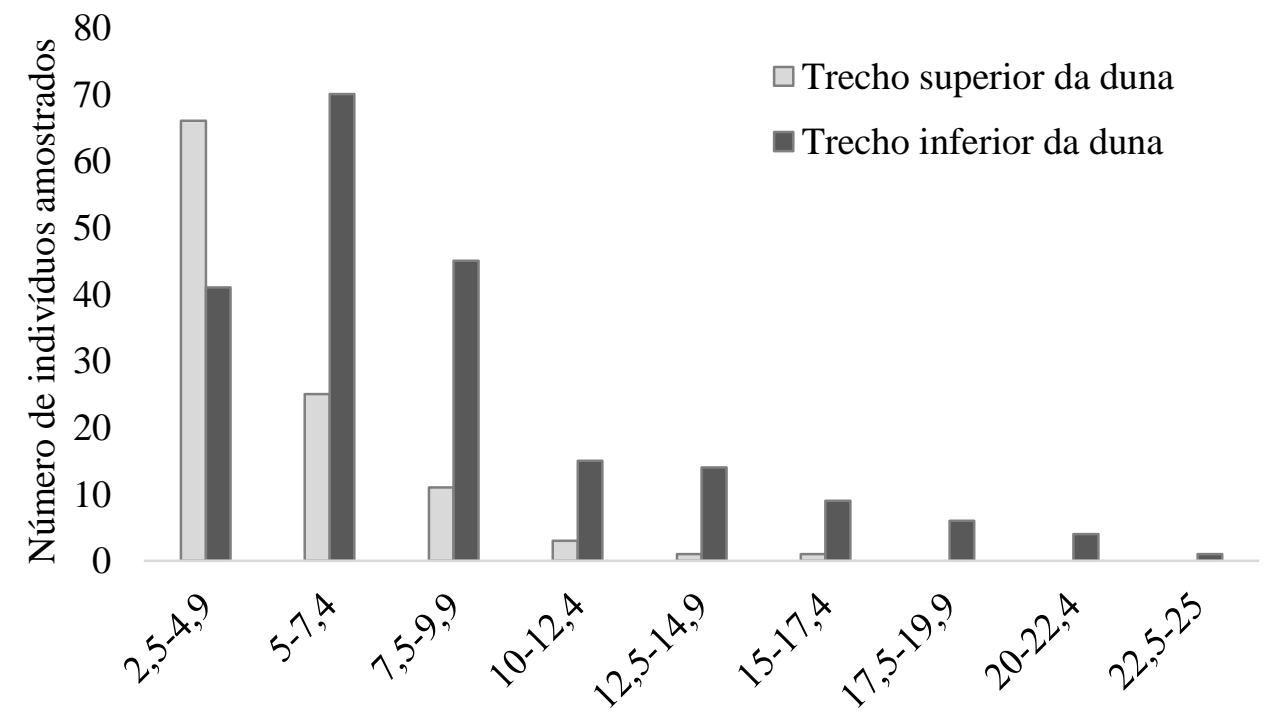

Classes de diâmetro

Figura 3. Distribuição em classes diamétricas do componente arbustivo-arbóreo na restinga da Lagoa do Arroio Corrente, município de Jaguaruna, Santa Catarina, Brasil. 
No trecho superior, ocorreu grande quantidade de indivíduos pequenos e finos e com muitas ramificações devido a pressões diferenciadas como luminosidade e ventos em excesso, além de baixos níveis de nutrientes (Sztutman e Rodrigues, 2002). Diferentemente, no trecho inferior, os indivíduos se apresentaram com diâmetros maiores (Figura 3).

Analisando o componente arbustivo-arbóreo em relação aos grupos ecológicos, das espécies encontradas no trecho superior, $83 \%$ foram classificadas como de início de sucessão (pioneiras + secundárias iniciais) e no trecho inferior foi de $76 \%$ (Figura 4).

A zoocoria representou, no trecho superior, $78 \%$ das espécies amostradas e no trecho inferior, 89\%. Esse padrão também foi identificado por outros autores (Scherer et al., 2005; Santos et al., 2012) no componente arbustivo-arbóreo de restinga arenosa. Esses estudos ratificam a importância dos agentes bióticos no fluxo gênico em restingas arenosas, assemelhando-se ao resultado de vários autores, como o mais relevante modo de dispersão das espécies lenhosas na Floresta Atlântica.

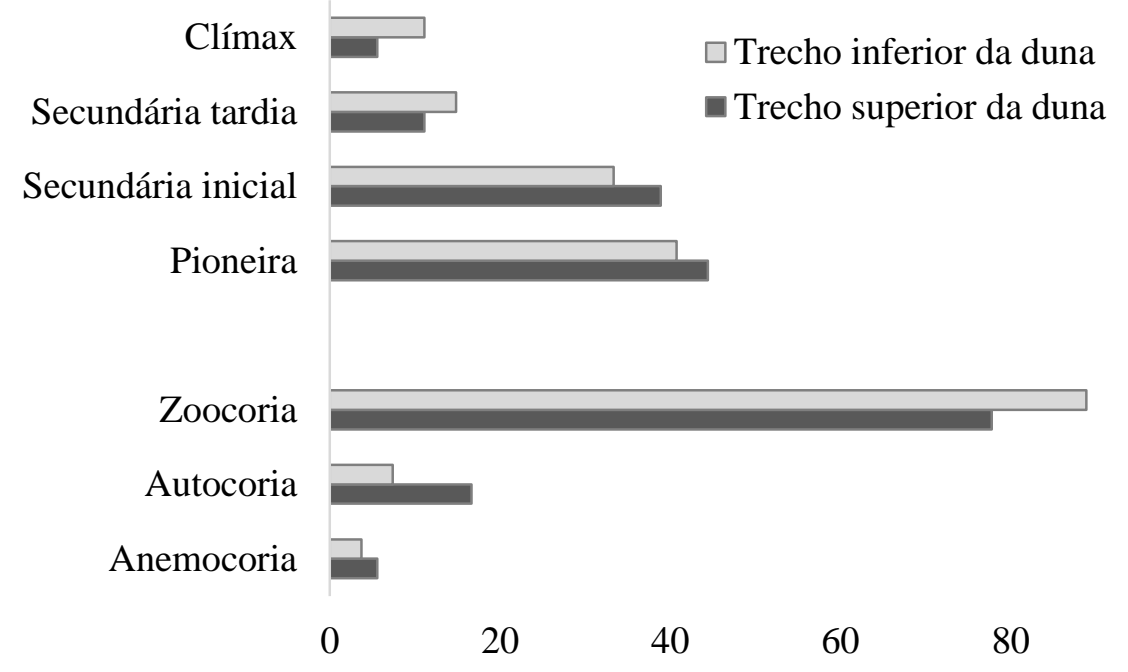

100

Figura 4. Distribuição (\%) em grupos ecológicos e em síndromes de dispersão das espécies do componente arbustivo-arbóreo na restinga da Lagoa do Arroio Corrente, município de Jaguaruna, Santa Catarina, Brasil.

\section{CONCLUSÃO}

A vegetação da restinga da Lagoa do Arroio Corrente apresentou, no trecho superior, estratificação de baixo porte, destacando-se as espécies arbustivas, apresentando aparência densa devido ao desenvolvimento aglomerado dessas plantas; e no trecho inferior, apresentou espécies arbóreas emergentes, conferindo dois estratos à vegetação, um mais baixo com predomínio de vegetação arbustiva e um segundo, com espécies arbóreas.

A heterogeneidade da vegetação de restinga não ficou evidenciada na restinga da Lagoa do Arroio Corrente, mesmo que, aparentemente, se reconheça pela altura dos indivíduos presentes, o reconhecimento de duas fitofisionomias distintas. Tal fato demonstra a complexidade a qual as comunidades vegetais de restinga apresentam, principalmente no que concerne aos diferentes condicionantes ambientais existentes no litoral brasileiro.

A espécie Guapira opposita possui a maior frequência, densidade e dominância, tanto no trecho superior, quanto no inferior, refletindo sua elevada plasticidade ecológica e a sua capacidade de adaptação a ambientes estressantes.

As análises efetuadas contribuíram com dados estruturais para as restingas de Santa Catarina, podendo auxiliar na caracterização da vegetação dos cordões arenosos do sul do 
Brasil.

As informações obtidas podem ser utilizadas para indicar espécies com potencialidades para restauração ecológica da mata ciliar no entorno da Lagoa do Arroio Corrente, já que é utilizada para abastecimento público e, no passado, sofreu impacto pela utilização em sua margem direita, para pastejo de gado bovino e para cultivo agrícola, atividades hoje proibidas.

\section{REFERENCIAS}

ALMEIDA JUNIOR, E. B.; SANTOS-FILHO, F. S.; ARAÚJO, E. L.; ZICKEL, C. S. Structural characterization of the woody plants in restinga of Brazil. Journal of Ecology and the Natural Environment, v. 3, n. 3, p. 95-103, 2011.

ALVARES, C. A.; STAPE, J. L.; SENTElHAS, P. C.; GONÇALVES, J. L. M.; SPAROVEK, G. Köppen's climate classification map for Brazil. Meteorologische Zeitschrift, v. 22, n. 6, p. 711-728, 2013. https://doi.org/10.1127/0941-2948/2013/0507

ARAUJO. D. S. D. Análise florística e fitogeográfica das restingas do estado do Rio de Janeiro. 2000. Tese (Doutorado em Ecologia) - Universidade Federal do Rio de Janeiro, Rio de Janeiro, 2000.

ASSUMPÇÃO, J.; NASCIMENTO, M. T. Estrutura e composição florística de quatro formações vegetais de restinga no complexo lagunar Grussaí/Iquipari, São João da Barra, RJ, Brasil. Acta botanica brasilica, v. 14, n. 3, p. 301-315, 2000. http://dx.doi.org/10.1590/S0102-33062000000300007

BACK, A. Caracterização climática. In: MILIOLI, G; SANTOS, R.; CITADINI-ZANETTE, V. Mineração de carvão, meio ambiente e desenvolvimento sustentável no sul de Santa Catarina. Curitiba: Juruá, 2009. p. 17-33.

BOSA, D. M.; PACHECO, D.; PASETTO, M. R.; SANTOS, R. Florística e estrutura do componente arbóreo de uma Floresta Ombrófila Densa Montana em Santa Catarina, Brasil. Revista Árvore, v. 39, n. 1, p.49-58, 2015. http://dx.doi.org/10.1590/010067622015000100005

BRESOLIN, A. Flora da restinga da ilha de Santa Catarina. Ínsula, n. 10, p. 1-55, 1979.

BUDOWSKI, G. N. Distribution of tropical American rain forest species in the light of succession processes. Turrialba, v. 15, n. 1, p. 40-42, 1965.

COLONETTI, S.; CITADINI-ZANETTE, V.; MARTINS, R.; SANTOS, R.; ROCHA, E.; JARENCOW, J. A. Florística e estrutura fitossociológica em floresta ombrófila densa submontana na barragem do rio São Bento, Siderópolis, Estado de Santa Catarina. Acta Scientiarum. Biological Sciences, v. 31, n. 4, p. 397-405, 2009. http://dx.doi.org/10.4025/actascibiolsci.v31i4.3345

CUNHA, I. Desenvolvimento sustentável na costa brasileira. Revista Galega de Economia, v 14, p. 1-14, 2005.

EMBRAPA. Empresa Brasileira de Pesquisa Agropecuária. Sistema brasileiro de classificação de solos. 3. ed. Brasília: EMBRAPA, 2013. 353 p.

FALKENBERG, D. B. Aspecto da flora e da vegetação secundária da Restinga de Santa Catarina, sul do Brasil. Insula, n. 28, p. 1-30, 1999. 
FREIRE, M. S. B. Levantamento florístico do parque estadual das dunas do natal. Acta botanica brasilica, v. 4, n. 2, suppl. 1, p. 41-59, 1990. http://dx.doi.org/10.1590/S010233061990000300006

IBGE. Instituto Brasileiro de Geografia e Estatística. Manual Técnico da Vegetação Brasileira. Rio de Janeiro: IBGE, 2012. 274 p.

JARDIM BOTÂNICO DO RIO DE JANEIRO. Lista de espécies da flora do Brasil. 2016. Disponível em: http://floradobrasil.jbrj.gov.br/. Acesso em: 10 maio 2016.

KENT, M.; COKER, P. Vegetation description and analysis. London: Belhaven Press, 1992. $363 \mathrm{p}$.

KLEIN, A. S.; CITADINI-ZANETTE, V.; SANTOS, R. Florística e estrutura comunitária de restinga herbácea no município de Araranguá, Santa Catarina. Biotemas, v. 20, n. 3, p. 15-26, 2007.

KORTE, A.; GASPER, A. L.; KRUGER, A.; SEVEGNANI, L. Composição florística e estrutura das restingas de Santa Catarina, In: VIBRANS, A. C.; SEVEGNANI, L.; GASPER, A. L.; LINGNER, D. V. Floresta Ombrófila Densa. Edifurb, Blumenau, 2013. p. 285-309.

LEITE, P. F.; KLEIN, R. M. Vegetação. In: IBGE. Geografia do Brasil: Região Sul. Rio de Janeiro, 1990. p. 113-150.

LINDEMAN, C. A. M. Vegetação no Rio Grande do Sul. Porto Alegre: Universal, 1906. $365 \mathrm{p}$.

MAGNAGO, L. F. S.; MARTINS, S. V.; PEREIRA, O. J. Heterogeneidade florística das fitocenoses de restingas nos estados do Rio de Janeiro e Espírito Santo, Brasil. Revista Árvore, v. $35, \quad$ n. 2, p. 245-254, 2011. http://dx.doi.org/10.1590/S010067622011000200009

MARTINS, F. R. Estrutura de uma floresta mesófila. Campinas: Ed. Unicamp, 1991. 246 p.

MARTINS, R.; JARENKOW, J. A.; GIEHL, E. L. H.; CITADINI-ZANETTE, V.; SANTOS, R. Estrutura de uma floresta brejosa em substrato turfoso, sul de Santa Catarina, Brasil. Revista Árvore, v. 37, n. 2, p. 299-309, 2013. http://dx.doi.org/10.1590/S010067622013000200011

MELO JÚNIOR, J. C. F.; BOEGER, M. R. T. Riqueza, estrutura e interações edáficas em um gradiente de restinga do Parque Estadual do Acaraí, Estado de Santa Catarina, Brasil. Hoehnea, v. 42, n. 2, p. 207-232, 2015.

MORO, M. F.; MARTINS, F. R. Métodos de levantamento do componente arbóreo-arbustivo. In: FELFILI, J. M.; EISENLOHR, P. V.; MELO, M. M. R. F.; ANDRADE, L. A.; MEIRA NETO, J. A. A. (Ed.) Fitossociologia no Brasil: Métodos e Estudos de Caso. Viçosa, Editora da Universidade Federal de Viçosa, 2011. p. 174-212.

MUELLER-DOMBOIS, D.; ELLENBERG, H. Aims and methods of vegetation ecology. New Jersey: The blackburn press, 2002. 547 p.

PEARMAN, P. B.; GUISAN, A.; BROENNIMANN, O.; RANDIN, C. F. Niche dynamics in space and time. Trends in Ecology and Evolution, v. 23, n. 3, p. 149-158, 2008. http://dx.doi.org/10.1016/j.tree.2007.11.005 
RAMBO, B. História da flora do litoral rio-grandense. Sellowia, n. 6, p. 113-172, 1954.

RAMBO, B. A flora de Cambará. Anais Botânicos do Herbário Barbosa Rodrigues, v. 1, n. 1, p. 111-135, 1949.

REITZ, P. R. Vegetação de Laguna (Santa Catarina). Sellowia, v. 6, n. 6, p. 243-258, 1954.

REITZ, R. (ed.). Vegetação da zona marítima de Santa Catarina. Anais Botânicos do Herbário Barbosa Rodrigues, n. 13, p. 17-115, 1961.

REITZ, R. Rosáceas. Itajaí: HBR, 1996. 135 p.

REITZ, R. Nictagináceas. Itajaí: HBR, 1970. 52 p.

ROCHA, C. F. D; VAN SLUYS, M; BERGALlO, H. G.; ALVES, M. A. S. Endemic and threatened tetrapods in the restingas of the biodiversity corridors of Serra do Mar and of the central da Mata Atlântica in Eastern. Brazilian Journal of Biology, v. 65, n. 1, p. 159-168, 2005. http://dx.doi.org/10.1590/S1519-69842005000100019

SACRAMENTO, A. C.; ZICKEL, C. S.; ALMEIDA JUNIOR, E. B. Aspectos florísticos da vegetação de restinga no litoral de Pernambuco. Revista Árvore, v. 31, n. 6, p. 11211130, 2007.

SAMPAIO, D.; SOUZA, V. C.; OLIVEIRA, A. A.; PAULA-SOUZA, J.; RODRIGUES, R. R. Árvores da Restinga: guia ilustrado para identificação das espécies da Ilha do Cardoso. São Paulo: Neotrópica, 2005.

SANTA CATARINA. Conselho Estadual de Meio Ambiente - CONSEMA. Resolução n. 51/2014. Lista oficial das espécies da flora ameaçada de extinção no estado de Santa Catarina. 2014. Acesso em: 10 maio 2016. Disponível em: https://goo.gl/uADUcv.

SANTOS, M.; FERMINO JUNIOR, P. C. P.; VAILATI, M. G.; PAUlilO, M. T. S. Aspectos estruturais de folhas de indivíduos de Guapira opposita (Vell) Reitz (Nyctaginaceae) ocorrentes em Restinga e na Floresta Ombrófila Densa. Insula, n. 39, p. 59-78, 2010. 10.5007/2178-4574.2010v39p59

SANTOS, R.; SILVA, R. C.; PACHECO, D.; MARTINS, R.; CITADINI-ZANETTE, V. Florística e estrutura do componente arbustivo-arbóreo de mata de restinga arenosa no Parque Estadual de Itapeva, Rio Grande do Sul. Revista Árvore, v. 36, n. 6, p. 1047 1059, 2012. http://dx.doi.org/10.1590/S0100-67622012000600006

SCARANO, F. R. Structure, function and floristic relantioships of plants communities in stressful habitats marginal to Brazilian Atlantic Rainforest. Annals of Botany, v. 90, p. 517-524, 2002.

SCARANO, F. R.; DUARTE, H. M.; RIBEIRO, K. T.; RODRIGUES, P. J. F. P.; BARCELLOS, E. M. B.; FRANCO, C. et al. Four sites with contrasting environmental stress in southeastern Brazil: relations of species, life form diversity, and geographical distribution to ecophysiological parameters. Botanical Journal of the Linnean Society, v. 136, p. 345-364, 2001. http://dx.doi.org/10.1111/j.1095-8339.2001. tb00579.x

SCHERER, A.; MARASCHIN-SILVA, F.; BAPTISTA, L. R. M. Florística e estrutura do componente arbóreo de matas de restinga arenosa no Parque Estadual de Itapuã, RS, Brasil. Acta botanica brasilica, v. 19, n. 4, p. 717-726, 2005. http://dx.doi.org/10.1590/S0102-33062005000400006 
SCHERER, A., MARASCHIN-SILVA, F.; BAPTISTA, L. R. M. Estrutura do componente arbóreo em remanescentes florestais nas Restingas sul brasileiras. Revista Brasileira de Biociências, v. 7, n. 4, p. 354-363, 2009.

SEVEGNANI, L.; COMTOIS, P. Olhares sobre a biodiversidade. In: SEVEGNANI, L.; SCHOEDER, E. Biodiversidade Catarinense: características, potencialidades e ameaças. Blumenau: Edifurb, 2013. p. 30-53.

SEVEGNANI, L.; VIBRANS, A. C.; GASPER, A. L. Considerações finais sobre a Floresta Ombrófila Densa e Restinga. In: VIBRANS, A. C.; SEVEGNANI, L.; GASPER, A. L.; LINGNER, D. V. (Ed.). Inventário florístico florestal de Santa Catarina: Floresta Ombrófila Densa. Blumenau: Edifurb, 2013. p. 325-327.

SILVA, S. M.; BRITEZ, R. M. A vegetação da Planície Costeira. In: MARQUES, M. C. M.; BRITEZ, R. M. (Org.). História natural e conservação da Ilha do Mel. Curitiba: Universidade Federal do Paraná, 2005. p.49-84.

SILVA, S. S. L.; ZICKEL, C. S.; CESTARO, L. A. Flora vascular e perfil fisionômico de uma restinga no litoral sul de Pernambuco, Brasil. Acta botanica brasilica, v. 22, n. 4, p. 1123-1135, 2008. http://dx.doi.org/10.1590/S0102-33062008000400023

SZTUTMAN, M.; RODRIGUES, R. R. O mosaico vegetacional numa área de floresta contínua da planície litorânea, Parque Estadual da Campina do Encantado, PariqueraAçu, SP. Revista Brasileira de Botânica, v. 25, n. 2, p. 61-176, 2002.

TABARELLI, M.; PERES, C. A. Abiotic and vertebrate seed dispersal in Brazilian Atlantic Forest: implications for forest regeneration. Biological Conservation, v. 106, n. 2, p. 165-176, 2002. http://dx.doi.org/10.1016/S0006-3207(01)00243-9

VAN der PIJL, L. Principles of dispersal in higher plants. 2. ed. Berlim: Springer-Verlag, 1972. 